\title{
EDUCAÇÃO NÃO FORMAL E CONTINUADA: UMA CONTRIBUIÇÃO DO DESIGN PARA O EMPODERAMENTO DE IDOSOS INSTITUCIONALIZADOS POR MEIO DE OFICINAS
}

Rafaella Santos Rêda

Universidade de Minas Gerais

rafaellareda@gmail.com

Nicholas Maximo Moreira Monteiro

Universidade de Minas Gerais

nicholasmaximo@outlook
Prof. Dr. Edson José Carpintero Rezende

Universidade de Minas Gerais

edson.carpintero@gmail.com

Resumo: A educação e o convívio social são fatores essenciais em qualquer idade, e na velhice em especial, pois ha que se considerar o significativo aumento da população idosa. O presente artigo relata a experiência de execução de duas oficinas que interligaram saberes de estudantes de Design de Produto da Universidade do Estado de Minas Gerais aos saberes passados através da história oral por idosos institucionalizados. Foram realizadas oficinas a partir dos saberes identificados. Os desafios e resultados obtidos com o projeto levaram a uma nova visão quanto ao envelhecimento ativo, uma vez que foi percebido que os idosos estão mais carentes de contado social, que de prática de exercícios físicos e mentais.

Palavras-chaves: idoso, design, envelhecimento ativo, empoderamento, educação não formal.

Abstract: Education and social life are essential at any age, especially at old age, since the significant rise in elderly population must be considered. This article reports the experience of running two workshops which interconnected knowledge of students of the Product Design of the State University of Minas Gerais to knowledge passed through oral history by the institutionalized elderly. Workshops were organized based on the identified knowledge. The challenges and results obtained from the project led to a new vision for the active aging, since it was realized that the elderly are most in need of social activities, than physical and mental exercises.

Keywords: elderly, design, active aging, empowerment, non-formal education. 


\section{INTRODUÇÃO}

O envelhecimento populacional é uma das maiores preocupações da saúde pública atual. No Brasil, em especial, ocorreu uma das transições mais rápidas do mundo. Foi somente em meados de 1940 que se notou declínio nas taxas de mortalidade e diminuição na taxa de natalidade. O consequente aumento na expectativa de vida ocorreu devido às melhorias na saúde pública e na infraestrutura urbana, além de avanços nas indústrias químico-farmacêutica da década de 1930. A partir de 1960, a mudança no padrão demográfico brasileiro fica ainda mais evidente, com aumento de $500 \%$ de idosos em quarenta anos (IBGE; 2009; LIMA-COSTA; VERAS, 2003). A súbita alteração na pirâmide etária, no Brasil, foi acompanhada de uma melhoria na saúde pública, porém, o mesmo não ocorreu em relação à mudança social, diferentemente dos países desenvolvidos, em que o envelhecimento populacional foi um processo gradual, seguido de desenvolvimento socioeconômico (WORLD HEALTH ORGANIZATION, 2002; FRANK, et. al, 2007).

Medidas para manter os idosos saudáveis e ativos socialmente são imprescindíveis, sobretudo em países em desenvolvimento. A população envelhecendo de forma saudável física e mentalmente, estará apta a trabalhar por mais tempo, podendo, assim, retardar políticas públicas de aposentadoria e pensão (HELPAGE INTERNATIONAL, 2012; WORLD HEALTH ORGANIZATION, 2002). Há sim uma diminuição das capacidades físicas e mentais na velhice, uma vez que a maioria dos idosos apresenta pelo menos uma doença crônica. Porém, mesmo com tais doenças, muitos levam uma vida normal, deixando de lado a esteriotipação do velho doente e acamado, impotente e dispendioso (ANDRADE NETO, 2010; RAMOS, 2003).

A questão, então, já não é viver por mais tempo, e sim viver por mais tempo de forma saudável, ativa e autônoma, sendo capaz de determinar e executar suas vontades (ANDRADE NETO, 2010; RAMOS, 2003). Pensando nisso, a Organização Mundial de Saúde propõe o envelhecimento ativo, processo de otimização do estilo de vida do idoso, com mais oportunidades e maior segurança, além de uma expectativa de vida mais funcional, que leve em consideração a saúde mental, além da saúde física (BESSA; SILVA, 2008; WORLD HEALTH ORGANIZATION, 2002). É importante ressaltar a questão da saúde mental, pois está estritamente ligada com doenças crônicodegenerativas, altamente presente em idosos (DE FREITAS, 2006; JORGE, 2008). Pensando nisso, Rezende; Sampaio; Ishitani (2004) relataram que medidas como integração social e profissional e ações educativas, além de assistência e tratamento, podem ajudar a retardar ou até mesmo reduzir o número de casos de doenças crônicodegenerativas.

Com o envelhecimento vêm também as perdas. Perda de pessoas próximas e de capacidade funcional, gerando, consequentemente, um grande abalo psicológico, que pode comprometer o autocuidado e a realização das atividades da vida diária (FRANK, et. al, 2007; RAMOS, et. al, 2002). A relação social é a melhor forma de reduzir o estresse de tais perdas, porém ao perceber que as funções desenvolvidas na sociedade mudaram, devido às alterações biológicas vindas com a última etapa do ciclo vital, muitos idosos se sentem impotentes e incapazes, motivo pelo qual se afastam do convívio social (CARNEIRO, 2007; SILVEIRA; PASQUALOTTI; COLUSSI, 2012). No entanto, tal convívio, principalmente com familiares e amigos, é de fundamental 
importância, uma vez que se sentir amado é um grande passo para se ter uma alta autoestima (CICIRELLI, 1990; SILVERSTEIN; BENGSTON, 1994).

Outro passo é a educação, durante toda a vida do indivíduo, incluindo a terceira idade. A educação influencia diretamente na qualidade e no estilo de vida (FRANÇA, 2011). A educação continuada é o modo eficaz de trazer a preservação da consciência de suas capacidades para o idoso e é o caminho ideal para o envelhecimento ativo, pois além de melhorar a qualidade de seu psicológico e emocional, ajuda, também, no combate a inúmeras doenças (FRAQUELLI, 2008; WORLD HEALTH ORGANIZATION, 2002). Todos os idosos têm o direito de acesso à educação continuada, a qual pode ocorrer de várias maneiras: dentro de sua própria casa, ou em grupos, como em oficinas didáticas e pedagógicas, que trabalham diversos conhecimentos, mantendo-os em aprendizado constante e dentro da necessidade individual (PEDUZZI, 2009).

A oficina em dinâmicas é uma forma efetiva de proporcionar educação continuada para idosos. Para Afonso (2007), a oficina se caracteriza como uma ação de intervenção psicossocial, que se diferencia de um grupo de terapia por apresentar um foco limitado e não haver uma analise psicológica profunda dos envolvidos. Também não se pode definir apenas como um projeto pedagógico, por levar em consideração situações pessoais. O convívio em grupo entre idosos os ajuda na autovalorização e possibilita a identificação de novos papeis (aptidões), mudando a concepção de senis, para idosos ativos e inseridos na sociedade em seus diversos aspectos: cultural, social, econômico e político (FRAQUELLI, 2008). As oficinas não são somente meio de educação continuada, como também de educação não formal. Essa forma de ensino tem ganhado destaque por abranger uma maior parte da população, passando o conhecimento de forma mais descontraída, fora dos ambientes escolares. Para os idosos, em especial, a educação não formal deve ter um intuito mais amplo, de passar conhecimento que os motivem a buscar melhores condições sociais, não permitindo que aceitem o que lhes é imposto (MARCONDES, 2004).

É importante se preocupar com a velhice desde o nascimento, optando por hábitos saudáveis, planejando uma garantia financeira e ficando atento quanto à aprendizagem continuada. Porém, ainda é possível que os indivíduos que já estão na terceira idade desfrutem desses benefícios. Pensando nisso, a pesquisa a seguir relata as experiências vivenciadas em duas oficinas em um Lar de Idosos, localizado em Belo Horizonte, Minas Gerais, que tiveram como objetivo avaliar a troca de saberes entre idosos institucionalizados.

\section{METODOLOGIA}

As oficinas aconteceram em um Lar de Idosos localizado em Belo Horizonte, Minas Gerais, e foram planejadas segundo as estruturas projetuais do design. O lar é uma instituição filantrópica, sem fins lucrativos que recebe pessoas carentes encaminhadas pela Prefeitura Municipal de Belo Horizonte, a partir dos 60 anos de idade. Atualmente abriga 35 idosos, sendo 12 homens e 23 mulheres e conta com o apoio de 29 funcionários.

O estudo representa uma pesquisa qualitativa realizada por alunos e professor orientador do curso de Design de Produto da Universidade do Estado de Minas Gerais (UEMG). Antes do começo do projeto de pesquisa, o diretor da instituição assinou um termo de anuência concordando com tal atividade e encaminhou os pesquisadores 
para uma conversa com a assistente social do lar. Na conversa foram explicados os objetivos propostos pela pesquisa e, juntamente com a profissional, a metodologia pretendida foi sendo adaptada para a realidade da instituição e de seus moradores.

Tal estudo teve inicio com o projeto de pesquisa intitulado "Design e educação não formal contribuindo para o empoderamento de idosos institucionalizados" de Rezende, Monteiro e Rêda (2015), o qual utilizou a história oral para identificar saberes individuais apreendidos durante toda a vida dos idosos institucionalizados, ocorrido entre 2014 e 2015.

Após identificados os principais saberes (culinária e artesanato) foi feita uma lista de possíveis cursos a serem ofertados em oficinas que contemplasse tais aptidões. Dessa forma, grande parte dos idosos poderia se interessar em participar da pesquisa. Ainda foi preciso levar em consideração as limitações, principalmente motoras, dos idosos. Portanto, objetos finos, pequenos ou pesados não poderiam ser utilizados nas oficinas.

A primeira oficina foi à confecção da capa de um livro de receitas e aconteceu no próprio Lar de Idosos. Teve ao todo onze idosos participantes, sendo oito mulheres e três homens, além de três funcionarias do lar, do orientador do projeto de pesquisa, da bolsista e de um aluno voluntário. Dentre os componentes, houve dois idosos que apresentam um quadro reconhecido de demência e/ou limitações cognitivas. Por isso demandaram mais ajuda dos participantes do projeto de pesquisa e das funcionárias do lar.

O objetivo inicial da primeira oficina era que todas as receitas do livro fossem passadas pelos próprios idosos do lar, porém inicialmente apenas três idosos, sendo um homem e duas mulheres, sabiam e lembraram-se de receitas, completando sete receitas ao todo. Assim, os demais participantes do projeto de pesquisa acrescentaram ao livro mais 17 receitas, que fossem de fácil execução. Depois de reunidas as receitas, elas foram encadernadas juntamente com uma capa e contra capa. Utilizou-se um pano xadrez externamente e também foram feitos pequenas representações de aventais em EVA e fita, de três cores diferentes, sendo elas azuis, vermelhas e amarelas. Além dos aventais, os participantes da oficina puderam enfeitar a capa do livro de receitas com diferentes tipos de botões e várias miçangas, uma vez que o dia da oficina do projeto coincidiu com o dia em que os idosos têm oficina de bijuteria. Depois de terminadas as capas, tiraram-se fotos de cada idoso com suas criações, que foram reveladas e coladas no livro de receitas. 


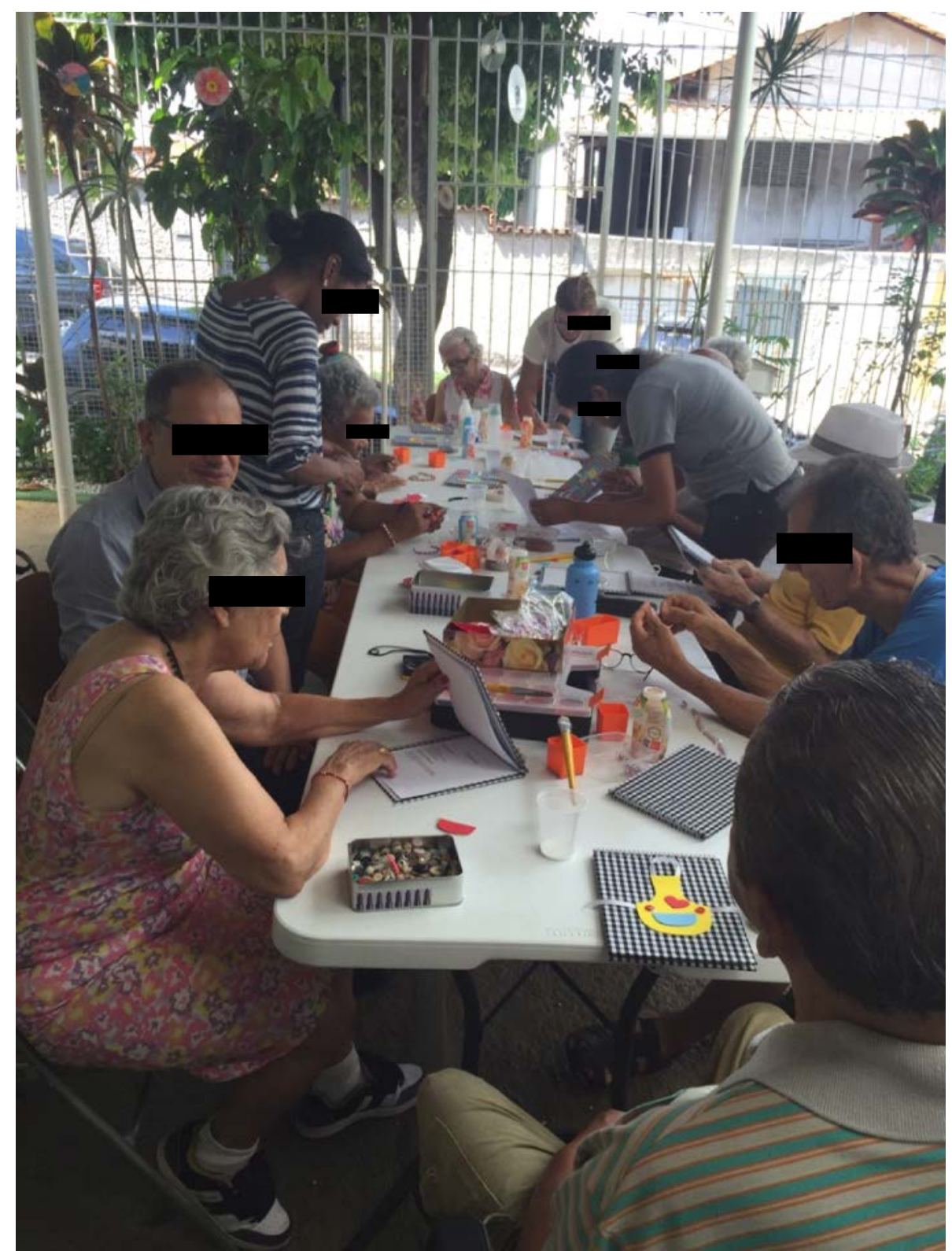

Figura 1- Oficina de confecção da capa do livro de receitas

Fonte: Elaborado pelo autor, com base na pesquisa realizada.

Na segunda oficina foi feita uma das receitas passadas pelos idosos, o bolo "Pérola". Tal receita foi escolhida por ser simples e agradar grande parte dos moradores do Lar de Idosos. Seus ingredientes são: seis ovos, quatro medidas de farinha de trigo, três medidas de açúcar, um copo de leite, uma colher de chá de sal, uma colher de sopa de fermento e duas colheres de manteiga. Para preparar basta separar as claras das gemas e misturá-las até ficar "em neve", juntar todos os ingredientes, bater bem e, por fim, colocá-los em uma forma untada e assar.

A segunda oficina também aconteceu no Lar de Idosos e contou com a ajuda de duas funcionárias do lar, além da bolsista do projeto e de um aluno voluntário. Três idosas ajudaram a preparar a receita, incluindo a responsável por essa, a qual ficou apenas dando as instruções. Dez idosos assistiram á preparação do bolo. 


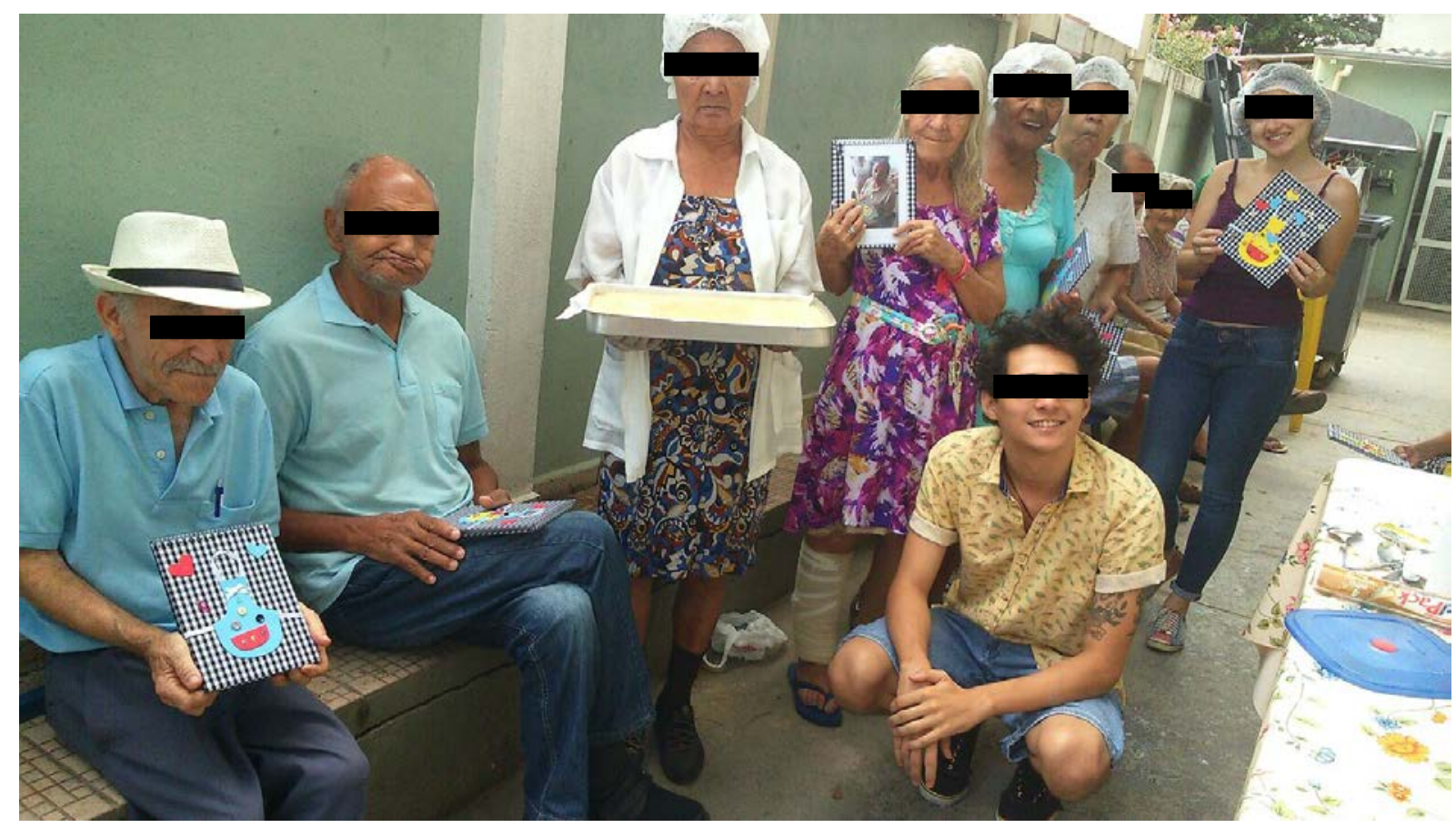

Figura 2- Oficina do bolo "Pérola"

Fonte: Elaborado pelo autor, com base na pesquisa realizada.

Aproveitou-se o momento da execução da receita para organizar um pequeno debate sobre o projeto de pesquisa, a fim de identificar se houve alguma mudança positiva quanto ao bem-estar físico, mental e social desses idosos a partir de seus relatos.

\section{CONCLUSÃO}

\subsection{Resultados e Discussão}

Depois de feitas as oficinas era esperado que houvesse um grupo focal com os participantes de todo o projeto, porém com os imprevistos ocorridos durante a execução do trabalho, como reforma no lar, falecimento de uma componente e internação de outras duas, o tempo entre as oficinas foi maior que o planejado. Com isso, observou-se que os idosos, no dia da segunda oficina, já não se lembravam claramente de como havia sido a primeira. Tendo isso como consideração foi decidido substituir o grupo focal por um pequeno debate, a fim de avaliar o impacto do projeto no envelhecimento ativo dos idosos.

Contudo, o resultado final do projeto foi positivo, uma vez que grande parte dos idosos demonstrou disposição durante as oficinas, querendo estar perto dos alunos e professor da Universidade do Estado de Minas Gerais (UEMG). Outros, mesmo mais tímidos, participaram das oficinas depois de um maior esforço e atenção por parte dos alunos e funcionárias do lar.

No primeiro contato com os idosos, houve certa preocupação, uma vez que eles não demonstraram interesse por oficinas, alegando já estarem velhos demais para aprender alguma coisa. Tal bloqueio dificultou a arrecadação de receitas, já que eles tiveram dificuldade em lembrar de comidas que tinham o costume de fazer/comer quando mais jovens. No entanto, quando viram os livros já encadernados, na primeira 
oficina (a criação de capa para o livro de receitas), houve grande entusiasmo e vários idosos queriam passar novas receitas para que seus nomes também aparecessem no livro.

Também na primeira oficina foi percebido maior interesse por parte das idosas, enquanto os idosos, apesar da curiosidade, tinham certo bloqueio em fazer trabalho artesanal. Contudo, o bloqueio foi se dissipando enquanto interagiam com os demais moradores do lar e, principalmente, com orientador e com os alunos da UEMG, sugerindo uma situação de carência que sentem por atenção de novas pessoas no lar.

$\mathrm{Na}$ segunda oficina, a preparação do "Bolo Pérola", houve pequena participação dos idosos, que alegaram sentir dor no braço, por isso não poderiam bater a clara em neve ou misturar a massa. No entanto, mesmo com a participação ativa de apenas três idosas, a maioria dos idosos que estava no lar foi presenciar a segunda oficina e mostraram entusiasmo em estarem reunidos em uma atividade diferente das praticadas semanalmente.

Principalmente durante o debate final com os idosos, pode-se perceber grande interesse por parte deles de continuar tendo oficinas e, acima disso, de que os estudantes fossem visitá-los mais vezes. A partir das oficinas e das visitas periódicas durante todo o ano do projeto de pesquisa foi percebido que foram poucos os idosos que se permitiram, logo nos primeiros encontros, socializar de forma mais estreita com os pesquisadores. No entanto, com o passar do tempo, os que antes eram mais tímidos, foram os que mais sentiram falta quando as visitas eram corriqueiras.

\subsection{Considerações finais}

Este artigo salientou a relevância das oficinas para idosos institucionalizados, sobretudo, em relação aos vínculos sociais. Os pesquisadores deste estudo veem as oficinas como espaço para colaboração da educação continuada não formal, essencial para que o envelhecimento ocorra de forma ativa e com maior chance de alta autoestima diante das mudanças sociais impostas pela velhice.

Conclui-se que além da preocupação com o envelhecimento ativo é necessário pensar nos idosos que já não conseguem alcançá-lo, ou seja, que possuem grandes dificuldades cognitivas ou doenças degenerativas. Tais idosos também possuem direito a inclusão social e a partir de pequenas ações, pautadas no design, que disponibilize cuidado e atenção já é, para eles, de grande valia e crescimento pessoal.

\section{REFERÊNCIAS}

AFONSO, M. L. M. Oficinas em dinâmica de grupo: um método de intervenção psicossocial. 2. ed. São Paulo: Casa do Psicólogo, 2007. 175 p.

ANDRADE NETO, M. L. Design para a longevidade: evidências no P\&D Design In: CONGRESSO BRASILEIRO DE PESQUISA E DESENVOLVIMENTO EM DESIGN, 9., 2010. São Paulo, SP. 12p.

BESSA, M. E. P.; SILVA, M. J. da. Motivações para o ingresso dos idosos em instituições de longa permanência e processos adaptativos: um estudo de caso. Texto Contexto Enferm. Florianópolis, v. 17, n. 2, abr./jun., 2008. p. 258-65. 
CARNEIRO, Rachel Shimba et al. Qualidade de vida, apoio social e depressão em idosos: relação com habilidades sociais. Psicologia: Reflexão e Crítica, v. 20, n. 2, p. 229-237, 2007.

CICIRELLI,V.G. Family support in relation to health problems of the elderly. In T.H. Brubaker (ed.), Family relationships in later life. 2nd ed.. Newbury Park, CA: Sage, p.212-228.

DE FREITAS, Sônia Maria, "História oral: procedimentos e possibilidades". Editora Humanitas, 2006.

FRANÇA, L. H. De F. P. O envelhecimento populacional e seu reflexo nas organizações: a importância da educação ao longo da vida. B. Téc. Senac: a R. Educ. Prof. Rio de Janeiro, v. 37, n. 2, mai./ago. 2011. P. 49-60.

FRANK, S. et. al. A avaliação da capacidade funcional: repensando a assistência ao idoso na Saúde Comunitária. Estudos Interdisciplinares do Envelhecimento, Porto Alegre, v. 11, p. 123-134, 2007.

FRAQUELLI, A. A. A relação entre auto-estima, auto imagem e qualidade de vida em idosos participantes de uma oficina de inclusão digital. 2008. $104 \mathrm{f}$. Dissertação (Mestrado em Gerontologia Biomédica) - Instituto de Geriatria e Gerontologia, PUCRS, Porto Alegre 2008.

HELPAGE INTERNATIONAL. Envelhecimento no século XXI: celebração e desafio. Fundo de População das Nações Unidas, Nova lorque; HelpAge International, Londres. 7 p., 2012.

IBGE. Indicadores sociodemográficos e de saúde no Brasil: 2009 / IBGE, Coordenação de População e Indicadores Sociais. Rio de Janeiro: IBGE, 2009.

JORGE, Maria Helena P. et al. A mortalidade de idosos no Brasil: a questão das causas mal definidas. Epidemiologia e Serviços de Saúde, v. 17, n. 4, p. 271-281, 2008.

LIMA-COSTA, Maria Fernanda; VERAS, Renato. Saúde pública e envelhecimento. Cadernos de Saúde Pública, v. 19, n. 3, p. 700-701, 2003.

MARCONDES, Maria da Glória Gohn. A educação não-formal e a relação escolacomunidade. EccoS Revista Científica, v. 6, n. 2, p. 39-65, 2004.

PEDUZZI, Marina et al. Atividades educativas de trabalhadores na atenção primária: concepções de educação permanente e de educação continuada em saúde presentes no cotidiano de Unidades Básicas de Saúde em São Paulo. Interface-Comunicação, Saúde, Educação, v. 13, n. 30, p. 121-134, 2009.

RAMOS, Luiz Roberto. Fatores determinantes do envelhecimento saudável em idosos residentes em centro urbano: Projeto Epidoso, São Paulo Determinant factors for healthy aging among senior citizens in a large city: the Epidoso. Cad. saúde pública, v. 19, n. 3, p. 793-798, 2003.

RAMOS, Marília P. et al. Apoio social e saúde entre idosos. Sociologias, v. 4, n. 7, 2002.

REZENDE, Edna Maria; SAMPAIO, Ivan Barbosa Machado; ISHITANI, Lenice Harumi. Causas múltiplas de morte por doenças crônico-degenerativas: uma análise multidimensional Multiple causes of death due to non-communicable diseases. Cad. Saúde Pública, v. 20, n. 5, p. 1223-1231, 2004. 
REZENDE, Edson José Carpintero; MONTEIRO, Nicholas Máximo Moreira; RÊDA, Rafaella Santos. Educação não formal e continuada: uma contribuição do design para o empoderamento de idosos institucionalizados por meio de oficinas. In: SEMINÁRIO DE PESQUISA E EXTENSÃO DA UEMG, 17, 2015, Carangola. Anais do 170 Seminário de Pesquisa e Extensão da UEMG. Carangola: UEMG, 2015. p. 1-1. CD-ROM. ISSN 22366164.

SILVEIRA, M. M. da; PASQUALOTTI, A.; COLUSSI, E. L. Educação gerontológica, envelhecimento humano e tecnologias educacionais: reflexões sobre velhice ativa. Estud. interdiscipl. envelhec. Porto Alegre, v.17, n. 2, 2012. p. 387-398.

SILVERSTEIN, Merril; BENGTSON, Vern L. Does intergenerational social support influence the psychological well-being of older parents? The contingencies of declining health and widowhood. Social science \& medicine, v. 38, n. 7, p. 943-957, 1994 WORLD HEALTH ORGANIZATION. Envelhecimento Ativo: uma política de saúde, Brasília, 60p, 2002. 